\title{
Predictors of yearly influenza vaccination in hospitalized and community based patients
}

\author{
Stephanie Attard Camilleri ${ }^{1 *}$, Juanita Camilleri Casingena ${ }^{2}$, Kentaro Yamagata ${ }^{1}$ and Martin Balzan ${ }^{1}$
}

\begin{abstract}
Background: Understanding positive and negative influences on adult immunization status can help healthcare providers to better identify and target patients who are likely to need immunization. Our aim was to assess and compare influenza and pneumococcal (IV/PV) immunisation rates to identify vaccination predictors in Malta.

Method: One group consisted of all medical patients discharged from Mater Dei Hospital (MDH) over a one week period in February 2013. Patients were administered a phone questionnaire. A second group of patients receiving community-based care at local health centres over a one week period in March 2013 were interviewed, identifying vaccination eligibility as per 2010 WHO recommendations.
\end{abstract}

Results: A total of 150 community (Mean age 61.5 SD 15.8, Male 60\%) and 149 hospitalised (Mean age 66.8, SD 13. $6 \%$, Male 48.3\%) patients in whom influenza vaccine was indicated were recruited. In the current year, 44 and $48.3 \%$ received the seasonal influenza vaccine, while 32.0 , and $49 \%$ vaccinated yearly respectively. Pneumococcal vaccination advice was less than $5 \%$ in both groups. On stepwise binary regression, vaccination predictors for the current year were regular yearly influenza vaccination (OR 93.62, Cl: 31.8-275.5, $p<0.001$ ) and vaccination reminders (OR 27.5, Cl: 9.63-78.31, $\mathrm{p}<0.001$ ). Nursing home residence (OR 5.78, Cl: 1.22-27.4,p=0.011), congestive cardiac failure (OR 2.11, Cl: 1.1-4.08, $p=0.02$ ) and diabetes mellitus (OR 1.68, Cl: 1.04-2.72, $p=0.034$ ) were all predictors for vaccination on exclusion of the strongest two predictors. For successive yearly vaccination, influenza vaccine recommendation by healthcare professionals (OR 12.35, Cl: 4.5-33.91, $p<0.001)$ and vaccination reminders (OR 5.99, Cl: 3.13-11.45, $p<0.01$ ) were main predictors. Congestive cardiac failure (OR 2.37, Cl: 1.20-4.7, $p=0.13$ ) and nursing home residence (OR 7.07, Cl: 1.45-34.5, $\mathrm{p}=0,005)$ were also positive predictors. Male gender was a negative predictor (OR 0.51, Cl: $0.31-0.83, p=0.006)$. Some of those who did not vaccinate were unaware of such need (40.5\% of community and $15.6 \%$ of hospitalised patients).

Conclusions: Just under half of the patient population received the IV during 2012-2013 period. Hospitalized patients are more likely to vaccinate regularly while a large proportion of community patients are unaware of the indication to vaccinate.

Keywords: Immunisation, Influenza vaccine, Pneumococcal vaccine

\section{Background}

The Advisory Committee on Immunization Practices (ACIP) and the World Health Organisation (WHO) 2012 recommendations advise yearly influenza vaccination as well as pneumococcal vaccination as shown in Tables 1 and 2 with mutual agreement towards vaccinating especially vulnerable groups such as the elderly, very young patients with chronic disease and the immunocompromised

\footnotetext{
* Correspondence: stephanie.b.camilleri@gov.mt

${ }^{1}$ Health-Mater Dei Hospital, Msida, Malta

Full list of author information is available at the end of the article
}

[1-6]. Evidence shows that influenza vaccination was associated with a lower admission rate from influenza complications, fewer deaths during the influenza season and decreased healthcare costs in the elderly and in the general population $[7,8]$. There are two types of pneumococcal vaccines $(\mathrm{PV})$ : pneumococcal conjugate vaccine 13 valent (PCV13) and pneumococcal polysaccharide vaccine 23 valent (PPSV 23). The PCV 13 is now recommended to all adults over 65 years old in addition to the previous recommendation of vaccinating the elderly $>65$ with PPSV23 [9]. The Capita trial showed that among older adults, PCV13

(c) The Author(s). 2018 Open Access This article is distributed under the terms of the Creative Commons Attribution 4.0 International License (http://creativecommons.org/licenses/by/4.0/), which permits unrestricted use, distribution, and 
Table $1 \mathrm{WHO}$ and ACIP recommendations for influenza vaccination 2012

\begin{tabular}{ll}
\hline Influenza Vaccination & \\
\hline WHO recommendations & ACIP recommendations \\
$\begin{array}{l}\text { Pregnant women at any } \\
\text { stage of pregnancy }\end{array}$ & Pregnant women and neonates \\
$\begin{array}{l}\text { Children aged } 6 \text { months to } \\
5 \text { years }\end{array}$ & $\begin{array}{l}\text { All persons more than } 6 \text { months who } \\
\text { do not have contraindications }\end{array}$ \\
$\begin{array}{l}\text { Elderly individuals } \\
>65 \text { years }\end{array}$ & Adults aged $>65$ years \\
$\begin{array}{l}\text { Individuals with chronic } \\
\text { medical conditions }\end{array}$ & Adults with chronic medical conditions \\
Healthcare workers & Immunocompromised persons \\
\hline
\end{tabular}

was effective in preventing vaccine-type pneumococcal, bacteremic, and nonbacteremic community-acquired pneumonia and vaccine-type invasive pneumococcal disease but not in preventing community-acquired pneumonia from any cause [10]. The most recent recommendation of administering the PCV13 to all older adults will be re-evaluated in 2018 by the ACIP [9].

This study was performed in Malta, an island state forming part of the European Union (population c. 412, 655, (2013). The National Immunisation Schedule in Malta includes the influenza vaccine, which is recommended for children aged 6 months to 5 years, elderly over 55 years of age, patients with chronic diseases, healthcare related occupations, as well as those in contact with at risk groups [11]. The pneumococcal vaccine has not been included in the local immunisation schedule to date, however, physicians may prescribe it and patients can purchase it from the private pharmacies.

The aim of this study was to determine the local Influenza Vaccine (IV) and Pneumococcal Vaccine (PV) uptake rates for the primary and the secondary healthcare populations and to identify predictors of vaccination.

\section{Method}

The study population consisted of patients in whom Influenza and/or pneumococcal Vaccination was indicated as per Table 1. A hospital group of adult patients (age >18) who were discharged after acute medical care at Mater Dei Hospital (MDH) from $21^{\text {st }}-28^{\text {th }}$ February 2013 from the department of medicine were contacted one week after discharge. $\mathrm{MDH}$ is the main University Hospital in Malta. The questionnaire was delivered via phone either in English or Maltese by 6 registered medical practitioners (Additional files 1 and 2, respectively). Questions 2 and 3 from the questionnaire identified patients eligible for vaccination and hence recruitement into the study. Their eligibility criteria were subsequently also confirmed by looking up information from discharge letters, cardiac laboratory database (for stress test, echocardiogram and
Table $2 \mathrm{WHO}$ and ACIP recommendations for pneumococcal vaccination 2012

\begin{tabular}{|c|c|}
\hline \multicolumn{2}{|l|}{ Pneumococcal Vaccination } \\
\hline WHO recommendations & ACIP recommendations \\
\hline $\begin{array}{l}\text { Healthy elderly (> } 65 \text { yrs. of } \\
\text { age), particularly those living in } \\
\text { institutions }\end{array}$ & All persons aged 65 years or more \\
\hline \multicolumn{2}{|l|}{ Patients with chronic organ failure } \\
\hline $\begin{array}{l}\text { Heart, lung, liver or kidney disease, } \\
\text { diabetes mellitus and alcoholism }\end{array}$ & $\begin{array}{l}\text { Chronic heart/lung/liver/kidney } \\
\text { disease, DM and alcoholism }\end{array}$ \\
\hline $\begin{array}{l}\text { Children }>2 \text { yrs. old at high risk for } \\
\text { disease (splenectomised children } \\
\text { and sickle-cell disease) }\end{array}$ & $\begin{array}{l}\text { Patients with leukaemia/ } \\
\text { lymphoma/multiple myeloma }\end{array}$ \\
\hline $\begin{array}{l}\text { Patients with immunodeficiencies } \\
\text { particularly those with functional } \\
\text { or anatomical asplenia }\end{array}$ & $\begin{array}{l}\text { Congenital/acquired } \\
\text { immunodeficiencies, } \\
\text { congenital/acquired asplenia; } \\
\text { splenic dysfunction or splenectomy; } \\
\text { organ transplantation or diseases } \\
\text { requiring immunosuppressive drugs }\end{array}$ \\
\hline Prevention of subsequent & Nephrotic syndrome \\
\hline
\end{tabular}
pneumococcal infection in patients recovering from proven or assumed pneumococcal pneumonia

HIV infection

Others including: cochlear implants, CSF leaks and cigarette smoking

coronary angiogram results) and the hospital laboratory database. A second group consisted of adult patients who received community-based healthcare services at three local public general practise health centres: Paola, Mosta and Floriana from $25^{\text {th }}-31^{\text {st }}$ March 2013. The three largest community based general practices serving the island were interviewed by 3 registered medical practitioners using the same questionnaire. Patients were asked whether they had taken the IV and/ or PV (PCV 13 and/ or PPSV 23) and the reason for vaccinating or not. The questionnaire also included a number of questions which could potentially be used to identify predictors of vaccination for winter 2012-2013 and for yearly vaccination. Yearly vaccination was defined as vaccination for 2 consecutive years prior to the study period.

The data collected was inputted using Microsoft Office Access ${ }^{\bullet}$ (Additional file 3) and analysed using Minitab 16 whilst binary logistic regression and stepwise regression were used to identify predictors of vaccination. A $p$ less than 0.05 was taken to represent statistical significance. The Fisher Test was used to compare the two population characteristics and vaccine eligibility characteristics (Tables 3-5).

\section{Results}

A total of 150 patients (60\% male; mean age 61.5, SD $15.8)$ receiving community based healthcare services and 149 patients (50\% male; mean age 66.5; SD 15.63) 
receiving MDH based healthcare services $(60.5 \%$ of total discharges, $14.4 \%$ of discharged patients were excluded due to non-eligibility for either vaccine whilst the remaining $25.1 \%$ of discharged patients could not be reached), were interviewed. Table 3 shows the characteristics and co-morbidities of these two population groups. Table 4 shows responses to questions related to vaccination whilst. Table 5 shows the univariate comparison of the two groups for influenza vaccination rates for each of the eligibility criteria.

138(46.2\%) patients (72, 48.3\% MDH group; 66, 44\% community group) took the influenza vaccine during winter 2012-2013. Fig. 1 (Reasons given by patients for taking the influenza vaccine for the winter 2012-2013) and 2 (Reasons given by patients for not taking the influenza vaccine for the winter 2012-2013) show reasons given by the patients for vaccinating or not vaccinating themselves during that winter for the $\mathrm{MDH}$ and the Community group of patients separately. Tables 6-8 show the binary logistic regression analysis with a stepwise selection model at $p=0.05$ used to identify predictors of yearly influenza vaccination and predictors for vaccination for the year 2012-2013.

\section{Discussion}

This study aimed to investigate vaccination in a hospital based setting after discharge and in the primary care setting during the consultation of eligible patients. Patients' eligibility was based on the WHO and ACIP criteria [2-6]. The hospital group was around 5 years older on average while the community group had a higher proportion of

Table 3 Patient demographics and co-morbidities

\begin{tabular}{lllll}
\hline Demographics & Community & $\begin{array}{l}\text { Hosp } \\
\text { Discharged }\end{array}$ & Total & $p$ \\
\hline Mean age & $n=150$ & $n=149$ & $n=299$ & \\
Males & $61.5+/-15.80$ & $66.5+/-15.63$ & 0.005 \\
Age Range & $n=89(59.3 \%)$ & $n=82(50 \%)$ & 0.097 \\
Co-morbidities & $18-90$ & $19-91$ & & \\
Age $>65$ & $89(59.3 \%)$ & $100(61 \%)$ & 189 & 0.77 \\
DM & $50(33.3 \%)$ & $63(38.4 \%)$ & 113 & 0.35 \\
IHD & $23(15.3 \%)$ & $49(29.9 \%)$ & 72 & 0.002 \\
CHF & $12(8.0 \%)$ & $35(21.3 \%)$ & 47 & 0.001 \\
CKD & $11(7.3 \%)$ & $97(59.5 \%)$ & 108 & $<0.0001$ \\
Lung disease & $30(20 \%)$ & $28(17.1 \%)$ & 58 & 0.5 \\
Liver disease & $2(1.3 \%)$ & $5(3 \%)$ & 7 & 0.26 \\
Alcohol abuse & $3(2.0 \%)$ & $4(2.4 \%)$ & 7 & 1 \\
Immune disease & $1(0.7 \%)$ & $5(3.1 \%)$ & 6 & 0.22 \\
Transplantation & $1(0.7 \%)$ & $2(1.2 \%)$ & 3 & 1 \\
\hline
\end{tabular}

males. Cardiac and renal co-morbidities were higher in the hospital group.

Numerous studies have been performed attempting to identify factors which influence influenza vaccine uptake rates. However, most of the previous research focuses on factors which influence vaccination in the same year for a specific subset of patients [12-16]. This study not only aimed to identify predictors of vaccination for the winter 2012-2013 for two distinct patient groups: hospital and community but also to identify predictors for yearly vaccination. Only one hospital was included, but this is the only acute hospital in Malta and therefore it is inclusive and representative of the whole population. Patients from the community included the 3 main general practice health centres in Malta with the largest catchment areas, and the only 3 health centres which are open $24 \mathrm{~h}$ a day. Whilst not a random sample, the study population broadly represented users of the public health care system.

On the other hand, the main weakness of the study was the difference in conducting the questionnaire between the 2 population groups. This was done face to face in the community and via telephone in the hospital population group. This could possibly have introduced a small degree of bias. Another limitation of the study was that the number of people with alcohol problems, immune disease and organ transplantation was too small. Undoubtedly local factors due to the culture and delivery of the health service probably had a significant impact on the results possibly limiting the generalizability of the results.

At the time of the study, pneumococcal vaccination in Malta was low and the main limiting factor for vaccination in both groups was physician recommendation. Seven (out of 150) patients from the primary health care setting and 6 (out of 149) patients from the secondary healthcare group were told to take the pneumococcal vaccine at some point in their life. From these patients, only 3 from the community-based population and 4 from the $\mathrm{MDH}$-based population actually took the vaccine. Lack of physician awareness on the importance of pneumococcal vaccination was the leading cause of low uptake rates in Malta. Another possible cause could be the fact that this vaccine has to be purchased by the patient as opposed to the free provision of influenza vaccine producing a financial barrier. Furthermore, since values for pneumococcal vaccine recommendation and uptake rates were too small, it was not possible to identify predictors of vaccination.

IV uptake, on the other hand, is comparatively higher than pneumococcal vaccination for both populations. Forty-nine per cent of the hospital based population and $32 \%$ of the community based population routinely take the IV every year with a significant difference between the two populations $(p=0.003)$. The data showed that 
Table 4 Pneumococcal and influenza vaccine eligibility, recommendations and uptake rates

\begin{tabular}{llll}
\hline & Community-based population & Hospital-based population \\
& $n=150$ & $n=149$ & $p$ \\
\hline IV taken this year & $66(44.0 \%)$ & $72(48.3 \%)$ & $73(49.0 \%)$ \\
IV taken yearly & $48(32.0 \%)$ & $6(4.0 \%)$ & 0.42 \\
PV advised & $7(4.7 \%)$ & $4(2.4 \%)$ & 1 \\
PV taken & $3(2.0 \%)$ & $81(54.4 \%)$ & 0.79 \\
Reminded this year & $76(51.3 \%)$ & $109(73.2 \%)$ & 0.56 \\
IV recommended & $97(64.7 \%)$ & & 0.13 \\
\hline
\end{tabular}

hospitalised patients had more renal and cardiac co-morbidities than those receiving community-based care. Furthermore, the presence of an acute episode requiring hospitalization could indicate a more severe form of disease, which in turn could generate fear of future episodes and hence a stronger will to vaccinate regularly. This is supported by the fact that $73 \%$ of the $\mathrm{MDH}$ population stated that they vaccinated to protect themselves compared to $63.6 \%$ from the community based population. Logistic regression in Table 7 identified cardiac disease, nursing home residence, and hospitalization as independent predictors for yearly vaccination. Unfortunately $40.5 \%$ of community patients who did not vaccinate were unaware of the indication (Fig. 2: Reasons given by patients for not taking the influenza vaccine for the winter 2012-2013).

Table 7 showed that male gender was a negative predictor for successive yearly vaccination. The effect of gender on vaccination rates in the general population varies from country to country. A previous study of influenza vaccine uptake has also shown that female gender was one of the best predictors of vaccination [16]. This study might reinforce a possibility that women could be more aware of influenza risk and the necessity to vaccinate themselves.

For the current year 2012-2013, the strongest predictors for vaccination were a history of yearly influenza vaccination and having received reminders to vaccinate (Table 8). This data supports other studies where the need for vaccination through physician recommendation and yearly reminders to vaccinate, represent potentially effective ways to improve uptake rate [16]. When the effect of physician recommendation was removed from the statistical model, having Diabetes Mellitus or Congestive Heart Failure and being a resident in an elderly home became statistically significant predictors for current year vaccination. One possible reason for this is that DM is a chronic disabling disease and these patients tend to be reviewed regularly at the diabetic clinic whilst patients with $\mathrm{CHF}$ tend to have acute life-threatening exacerbations. Thus, both these conditions carry a heavy disease burden possibly leading to more frequent contact with their caring physician. In Malta, it is common practice that patients residing in elderly homes are offered and given the influenza vaccine on a yearly basis in their residence thus IV is easily accessible. This could explain why living in an elderly home emerged as a predictor for influenza vaccination despite having few patients with this criterion in our study. Table 6 shows that having Chronic Kidney Disease just fails to be a statistically significant predictor for vaccination $(p=0.083)$ and was in fact eliminated by stepwise regression from the model. On the other hand, surprisingly, having chronic lung disease did not predict vaccination possibly either because

Table 5 Influenza vaccination rates per eligibility criteria

\begin{tabular}{|c|c|c|c|c|}
\hline & Hospital patient population $(n=149)$ & Community patient population $(n=150)$ & Total $(n=299)$ & $p$ \\
\hline & Take IV yearly & Take IV yearly & & \\
\hline Age $>65$ & $53 / 100(53.0 \%)$ & $35 / 89(39.3 \%)$ & $88 / 189(46.5 \%)$ & 0.0794 \\
\hline DM & $38 / 63(60.3 \%)$ & $15 / 50(30.0 \%)$ & $53 / 113(46.9 \%)$ & 0.0022 \\
\hline IHD & $27 / 49(55.1 \%)$ & $8 / 23(34.8 \%)$ & $35 / 72(48.6 \%)$ & 0.133 \\
\hline $\mathrm{CHF}$ & 23/35 (65.7\%) & $5 / 12(41.7 \%)$ & 28/47 (59.6) & 0.182 \\
\hline CKD & 46/97 (47.4\%) & $5 / 11(45.5 \%)$ & $51 / 110(46.4 \%)$ & 1 \\
\hline Lung disease & $12 / 28(42.9 \%)$ & 10/30 (33.3\%) & 22/58 (37.9) & 0.58 \\
\hline Resident in elderly home & $8 / 8(100 \%)$ & $2 / 4(50 \%)$ & 10/12 (83.3) & 0.09 \\
\hline Others* & 10/21 (47.6\%) & $6 / 15(40 \%)$ & $16 / 36(44.4 \%)$ & 0.65 \\
\hline
\end{tabular}

*Liver disease, organ transplantation, disorders of immune system, pregnancy, disability, alcohol abuse, health-related occupation 


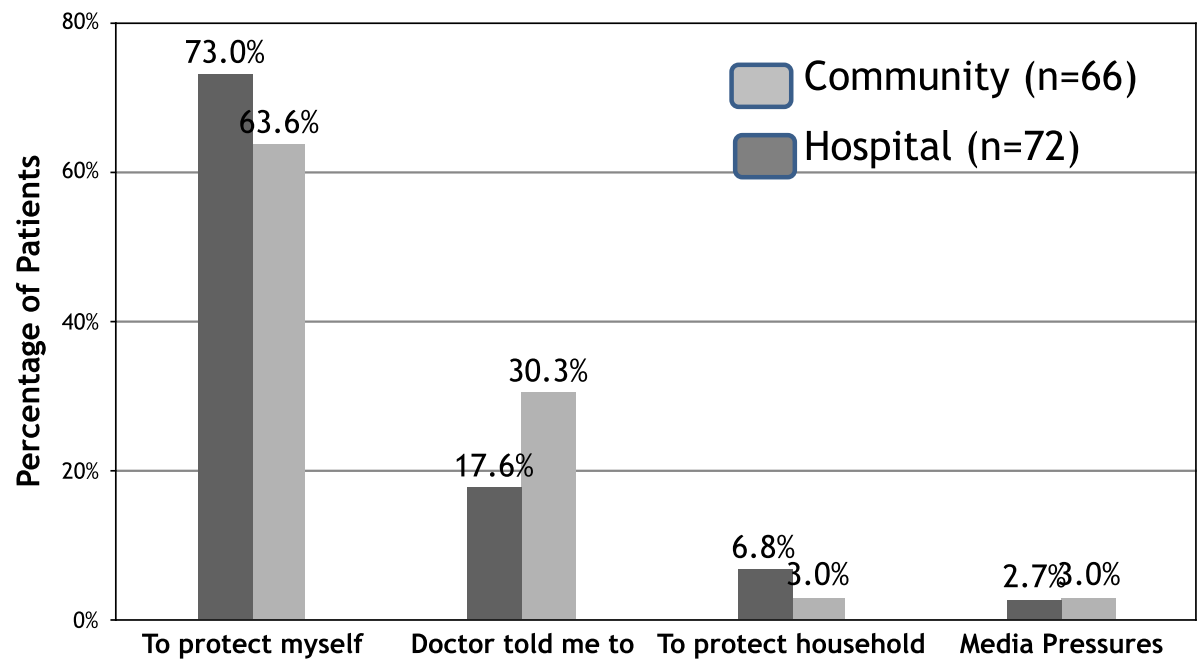

Fig. 1 Reasons given by patients for taking the influenza vaccine for the winter 2012-2013

respiratory disease might be milder and more intermittent or because a large proportion of our patient population are cared for by non-respiratory physicians or GPs.

The main reasons given by patients for taking the IV during the winter 2012-2013, were to protect themselves from serious disease (73\% for the hospital patient group; $63.6 \%$ for the community patient group) followed by physician recommendation (17.6\% hospital patient group; $30.3 \%$ community patient group). This compared well with results documented in both local studies [16] as well as published studies done abroad $[17,18]$. The fact that physician recommendation was the second commonest reason for vaccination given by the patients themselves was confirmed on multivariate analysis of the questionnaire.

Reasons for not vaccinating are similar between the primary and secondary care in our study, main reason being fear of side effects with $39.3 \%$ in the primary and

Table 6 Binary logistic regression model using all predictors (winter 2012/13)

\begin{tabular}{llll}
\hline Source & $P$ & & $95 \% \mathrm{Cl}$ \\
Model & 0.005 & Odds Ratio & \\
\hline Diabetes Mellitus & 0.017 & 1.823 & $1.111-2.99$ \\
Male Gender & 0.048 & 0.616 & $0.381-0.998$ \\
Chronic Heart Failure & 0.058 & 1.974 & $0.972-4.009$ \\
Chronic Renal Failure & 0.083 & 1.727 & $0.928-3.215$ \\
MDH/Community & 0.125 & 1.561 & $0.879-2.774$ \\
Alcohol abuse & 0.217 & 0.288 & $0.032-2.62$ \\
Age $\geq 65$ & 0.26 & 1.01 & $0.993-1.027$ \\
Liver disease & 0.413 & 0.491 & $0.085-2.846$ \\
Lung disease & 0.75 & 1.106 & $0.595-2.056$ \\
Ischaemic Heart Disease & 0.944 & 1.022 & $0.559-1.869$ \\
\hline
\end{tabular}

$36.7 \%$ in the secondary setting. This is also similar to the other Maltese study with $43 \%$ giving this reason [8]. Other reasons not to vaccinate in our study were unaware of indication (15.6\% MDH and $40.5 \%$ community) forgot/ had no time (22.1\% MDH and $13.1 \%$ community), feel they do not need to take it or that it doesn't work (20\% MDH and 6\% community) and history of contraindication to vaccinate $(5.6 \% \mathrm{MDH}$ and $1.2 \% \mathrm{com}-$ munity). In the study done by Thomas et al., $40.3 \%$ were not expecting to catch influenza and therefore thought it was unnecessary [17].

Increasing physician awareness and education on the importance of influenza vaccination would be expected to improve vaccine uptake rates through recommendation at each doctor-patient encounter.

\section{Conclusion}

The study examined vaccination rates for a group of medical patients recently discharged from an acute hospital and another group of patients receiving community-based care. Pneumococcal vaccination was low and the main

Table 7 Binary logistic regression to determine predictors for successive yearly vaccination

\begin{tabular}{llll}
\hline & Odds Ratio & $95 \% \mathrm{Cl}$ & $p$ \\
\hline Male Gender & 0.46 & $0.26-0.80$ & $p<0.001$ \\
IV recommendation & 12.38 & $4.62-33.16$ & $p<0.001$ \\
Reminder to take IV & 4.88 & $2.64-9.02$ & $p<0.01$ \\
On removal of the 2 strongest predictors & & \\
Male Gender & 0.48 & $0.29-0.77$ & 0.02 \\
Diabetes & 1.65 & $1.01-2.69$ & 0.047 \\
CHF Y/N & 2.80 & $1.44-5.44$ & 0.002 \\
Resident elderly home & 7.49 & $1.55-36.17$ & 0.004 \\
\hline
\end{tabular}




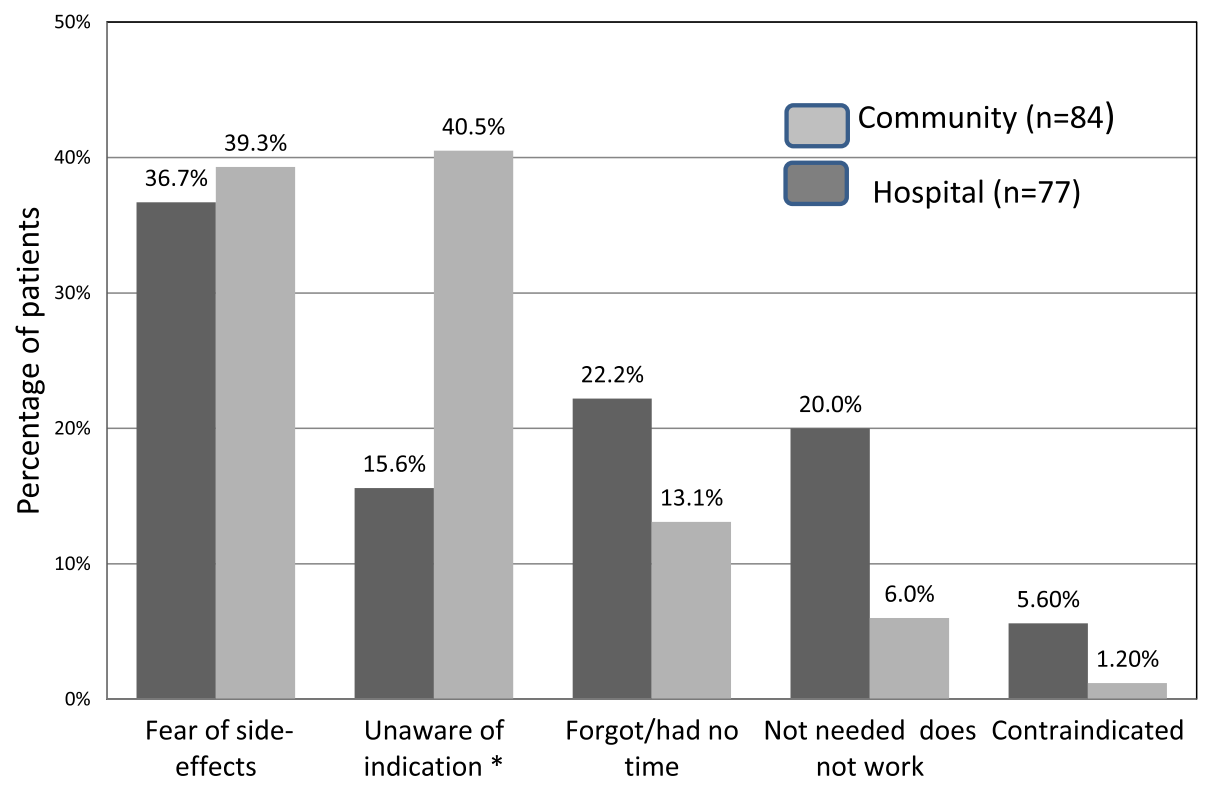

Fig. 2 Reasons given by patients for not taking the influenza vaccine for the winter 2012-2013. * Statistically significant difference between MDH and Community population ( $p=0.0003$ )

limiting factor was lack of physician recommendation. Hospitalized patients were older, and had more cardiac and renal co-morbidities. Influenza vaccination for the current year was the same in both groups, however, significantly more hospitalized patients vaccinated against influenza every year. This might be attributed to more frequent co-morbidity, more severe disease with possibly a stronger will to protect oneself. Predictors for yearly influenza vaccination included vaccine recommendation by healthcare professionals, reminding patients to vaccinate, residence in a nursing home, diabetes mellitus, congestive cardiac failure and female gender.

\section{Additional files}

Additional file 1: Study questionnaire in english. (DOCX $87 \mathrm{~kb}$ )

Additional file 2: Study questionnaire in maltese. (DOCX $87 \mathrm{~kb}$ )

Additional file 3: Study dataset. (XLSX $55 \mathrm{~kb}$ )

Table 8 Binary logistics regression to determine predictors for vaccination for the winter 2012/13

\begin{tabular}{|c|c|c|c|}
\hline & Odds Ratio & $95 \% \mathrm{Cl}$ & $p$ \\
\hline Yearly IV vaccination & 99.38 & $34.21-288.70$ & 0.0001 \\
\hline Reminder to take IV & 21.81 & $8.009-59.39$ & 0.0001 \\
\hline \multicolumn{4}{|c|}{ On removal of the 2 strongest predictors } \\
\hline Diabetes Mellitus & 1.804 & $1.12-2.90$ & 0.015 \\
\hline $\mathrm{CHF} Y / \mathrm{N}$ & 2.138 & $1.12-4.10$ & 0.02 \\
\hline Resident in nursing home & 6.455 & $1.37-30.37$ & 0.006 \\
\hline
\end{tabular}

\section{Abbreviations}

ACIP: Advisory Committee on Immunization Practices; CHF: Congestive heart failure; Cl: Confidence intervals; CKD: Chronic kidney disease; DM: Diabetes Mellitus; GP: General Practitioner; IV: Influenza vaccine; MDH: Mater Dei Hospital; OR: Odds ratio; PCV13: Pneumococcal Conjugate Vaccine 13 valent; PPSV23: Pneumococcal Polysaccharide Vaccine 23 valent; PV: Pneumococcal vaccine; SD: Standard deviation; WHO: World Health Organisation

\section{Acknowledgements}

We would like to acknowledge Dr. Christopher Zammit, Dr. David Bilocca, Dr. Ramon Casha, Dr. Yanika Gatt and Dr. Keith Debono for their contributions with data collection.

\section{Availability of data and materials}

All data generated or analysed during this study are included in this published article and its supplementary information files.

\section{Authors' contributions}

SAC collected and analysed data and was a major contributor in writing the manuscript. JCC collected data and contributed to manuscript writing. KY collected data and analysed data. MB analysed and interpreted data and supervised the study throughout. All authors read and approved the final manuscript.

\section{Ethics approval and consent to participate}

Authorisation for the study was given by the Mater Dei Hospital Data Protection Committee according to the local Data Protection Act on $25^{\text {th }}$ February 2013. The need for ethics approval was waived. All participants gave informed consent prior to each interview.

\section{Consent for publication}

Not applicable.

\section{Competing interests}

The authors declare that they have no competing interests.

\section{Publisher's Note}

Springer Nature remains neutral with regard to jurisdictional claims in published maps and institutional affiliations. 


\section{Author details}

${ }^{1}$ Health-Mater Dei Hospital, Msida, Malta. ${ }^{2}$ Health-Primary Health Care,

Bulawayo, Zimbabwe.

Received: 19 February 2018 Accepted: 10 June 2018

Published online: 01 August 2018

\section{References}

1. Ludwig E, Bonanni P, Rohde G, Sayiner A, Torres A. The remaining challenges of pneumococcal disease in adults. Eur Respir Rev. 2012;21(123): 57-65.

2. WHO position paper.Pneumococcal conjugate vaccine for childhood immunization - Wkly Epidemiol Rec 2007;82(12):93-104.

3. Updated recommendations for prevention of invasive pneumococcal disease among adults using the 23-valent pneumococcal polysaccharide vaccine (PPSV23). Morb Mortal Wkly Rep. 2010;59(1):1102-6.

4. Prevention and control of influenza with vaccines. Recommendations of the advisory committee on immunization practices (ACIP), 2011. Morb Mortal Wkly Rep. 2011;60(1):1128-32.

5. Nuorti J, Whitney C, Centers for Disease Control and Prevention (CDC) Prevention of pneumococcal disease among infants and children - use of 13-valent pneumococcal conjugate vaccine and 23-valent pneumococcal polysaccharide vaccine: recommendations of the advisory committee on immunization practices (ACIP). Morb Mortal Wkly Rep. 2010;59(1):1-18.

6. Influenza (Seasonal) [Internet]. World Health Organization. Influenza. Fact Sheet 211. 2009 [cited 20 February 2016]. Available from: http://www.who. int/mediacentre/factsheets/fs211/en/

7. Nichol K, Margolis K, Wuorenma J, Von Sternberg T. The efficacy and cost effectiveness of vaccination against influenza among elderly persons living in the community. N Engl J Med. 1994;331(12):778-84.

8. Bridges C, Thompson W, Meltzer M, Reeve G, Talamonti W, Cox N, et al. Effectiveness and cost-benefit of influenza vaccination of healthy working adults. JAMA. 2000;284(13):1655.

9. Tomczyk S, Bennett NM, Stoecker C, Gierke R, Moore MR, Whitney CG, et al. Use of 13-valent pneumococcal conjugate vaccine and 23-valent pneumococcal polysaccharide vaccine among adults aged $\geq 65$ years: recommendations of the advisory committee on immunization practice (ACIP). MMWR Morb Mortal Wkly Rep. 2014;63:822-5.

10. Bonten MJ, Huijts SM, Bolkenbaas M, Webber C, Patterson S, Gault S, et al. Polysaccharide Conjugate Vaccine against Pneumococcal Pneumonia in Adults. N Engl J Med. 2015;372(12):1114-25.

11. Influenza Vaccine [Internet]. Health.gov.mt. 2016 [cited 20 February 2016]. Available from: https://deputyprimeminister.gov.mt/en/phc/pchyhi/Pages/ Influenza-Vaccine.aspx

12. Heimberger T, Chang H, Shaikh M, Crotty L, Morse D, Birkhead G. Knowledge and attitudes of healthcare workers about influenza: why are they not getting vaccinated? Infect Control Hosp Epidemiol. 1995;16(7):412-5.

13. Kuster S, Tuite A, Kwong J, McGeer A, Fisman D. Evaluation of coseasonality of influenza and invasive pneumococcal disease: results from prospective surveillance. PLoS Med. 2011;8(6):e1001042.

14. Nichol K. The additive benefits of influenza and pneumococcal vaccinations during influenza seasons among elderly persons with chronic lung disease. Vaccine. 1999;17:591-3.

15. Xakellis G. Predictors of influenza immunization in persons over age 65. J Am Board Fam Med. 2005;18(5):426-33.

16. Asciak R, Balzan M, Buttigieg J. Predictors of seasonal influenza vaccination in chronic asthma. Multidiscip Respir Med. 2013;8(1):68.

17. Müller D, Szucs T. Influenza vaccination coverage rates in five european countries- a population based cross sectional analysis of two consecutive influenza seasons. Infection. 2007;35(5):308-19.

18. Szucs T, Wahle K, Müller D. Influenza vaccination in Germany. A populationbased cross-sectional analysis of three seasons between 2002 and 2005. Med Klin (Munich). 2006;101(7):537-45.

\section{Ready to submit your research? Choose BMC and benefit from:}

- fast, convenient online submission

- thorough peer review by experienced researchers in your field

- rapid publication on acceptance

- support for research data, including large and complex data types

- gold Open Access which fosters wider collaboration and increased citations

- maximum visibility for your research: over $100 \mathrm{M}$ website views per year

At BMC, research is always in progress.

Learn more biomedcentral.com/submissions 